\title{
Time interval to surgery and outcomes following the surgical treatment of acute traumatic subdural hematoma
}

\section{Citation}

Walcott, Brian P., Arjun Khanna, Churl-Su Kwon, H. Westley Phillips, Brian V. Nahed, and JeanValery Coumans. 2014. Time Interval to Surgery and Outcomes Following the Surgical Treatment of Acute Traumatic Subdural Hematoma. Journal of Clinical Neuroscience 21, no. 12: 2107-2111. doi:10.1016/j.jocn.2014.05.016.

\section{Published Version}

doi:10.1016/j.jocn.2014.05.016

\section{Permanent link}

http://nrs.harvard.edu/urn-3:HUL.InstRepos:37045419

\section{Terms of Use}

This article was downloaded from Harvard University's DASH repository, and is made available under the terms and conditions applicable to Open Access Policy Articles, as set forth at http:// nrs.harvard.edu/urn-3:HUL.InstRepos:dash.current.terms-of-use\#OAP

\section{Share Your Story}

The Harvard community has made this article openly available.

Please share how this access benefits you. Submit a story.

Accessibility 


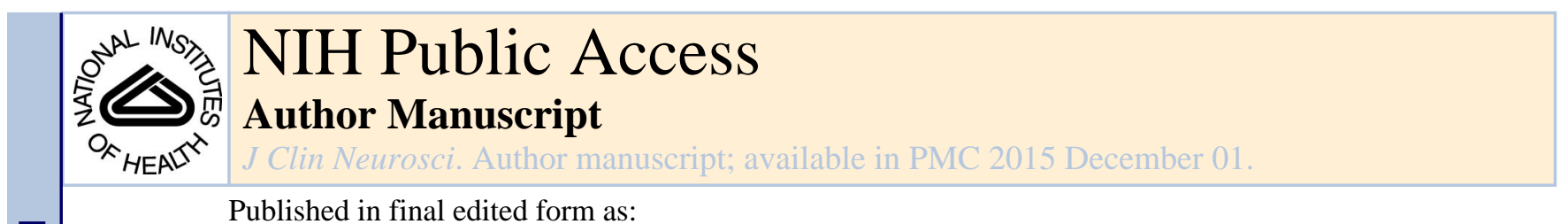

Published in final edited form as:

J Clin Neurosci. 2014 December ; 21(12): 2107-2111. doi:10.1016/j.jocn.2014.05.016.

\title{
Time interval to surgery and outcomes following the surgical treatment of acute traumatic subdural hematoma
}

\author{
Brian P. Walcott ${ }^{*}$, , Arjun Khanna ${ }^{1}$, Churl-Su Kwon, H. Westley Phillips, Brian V. Nahed, \\ and Jean-Valery Coumans \\ Department of Neurosurgery, Massachusetts General Hospital and Harvard Medical School, 55 \\ Fruit Street, White Building Room 502, Boston, MA 02114, USA
}

\section{Abstract}

Although the pre-surgical management of patients with acute traumatic subdural hematoma prioritizes rapid transport to the operating room, there is conflicting evidence regarding the importance of time interval from injury to surgery with regards to outcomes. We sought to determine the association of surgical timing with outcomes for subdural hematoma. A retrospective review was performed of 522 consecutive patients admitted to a single center from 2006-2012 who underwent emergent craniectomy for acute subdural hematoma. After excluding patients with unknown time of injury, penetrating trauma, concurrent cerebrovascular injury, epidural hematoma, or intraparenchymal hemorrhage greater than $30 \mathrm{~mL}$, there remained 45 patients identified for analysis. Using a multiple regression model, we examined the effect of surgical timing, in addition to other variables on in-hospital mortality (primary outcome), as well as the need for tracheostomy or gastrostomy (secondary outcome). We found that increasing injury severity score (odds ratio [OR] 1.146; 95\% confidence interval [CI] 1.035-1.270; $p=$ $0.009)$ and age (OR1.066; 95\% CI 1.006-1.129; $p=0.031)$ were associated with in-hospital mortality in multivariate analysis. In this model, increasing time to surgery was not associated with mortality, and in fact had a significant effect in decreasing mortality (OR 0.984; 95\%CI $0.971-0.997 ; p=0.018)$. Premorbid aspirin use was associated with a paradoxical decrease in mortality (OR $0.019 ; 95 \%$ CI $0.001-0.392 ; p=0.010)$. In this patient sample, shorter time interval from injury to surgery was not associated with better outcomes. While there are potential confounding factors, these findings support the evaluation of rigorous preoperative resuscitation as a priority in future study.

\section{Keywords}

Aspirin; Craniectomy; Gastrostomy; Subdural; Surgery; Tracheostomy; Trauma

(C) 2014 Elsevier Ltd. All rights reserved.

"Corresponding author. Tel.: +1 617726 2000; fax: +1 617643 4113. walcott.brian@mgh.harvard.edu (B.P. Walcott).

1 These authors have contributed equally to the manuscript.

Publisher's Disclaimer: This is a PDF file of an unedited manuscript that has been accepted for publication. As a service to our customers we are providing this early version of the manuscript. The manuscript will undergo copyediting, typesetting, and review of the resulting proof before it is published in its final citable form. Please note that during the production process errors may be discovered which could affect the content, and all legal disclaimers that apply to the journal pertain.

Conflicts of Interest/Disclosures

The authors declare that they have no financial or other conflicts of interest in relation to this research and its publication. 


\section{Introduction}

Acute, traumatic subdural hematoma (SDH) is one of the most devastating form of traumatic brain injury (TBI), with mortality rates estimated between $40-60 \%{ }^{1}$. In most situations, especially in patients with profound neurological deficits, SDH is considered a neurosurgical emergency requiring immediate evacuation of the hematoma ${ }^{2}$. However, there is some ambiguity regarding what factors influence outcomes following surgical treatment, making prognostication a challenge in these patients.

The effect of the amount of time that elapses between injury and surgery ("time to surgery") is of particular interest, as this is one of the few factors that may be under some clinical control. A report by Seelig et al. of 82 patients with SDH who presented as comatose and underwent surgery within 4 hours of injury had significantly lower mortality than patients who underwent surgery later, with mortality rates of $30 \%$ and $90 \%$, respectively. ${ }^{3}$ These data, published in 1981, suggested that faster times to surgery could significantly decrease mortality. Although a few other reports have corroborated this finding ${ }^{4,5}$, a number of subsequent studies have failed to find a similar effect of time to surgery on mortality, even with up to a 10 hour interval ${ }^{6-9}$. In fact, some studies have even reported a significant association between faster times to surgery and increased mortality rates ${ }^{10-12}$. While it is a commonly held belief in many neurotrauma centers that emergency surgery benefits patients, the overall body of evidence and lack of clinical trial data suggests that the association between outcomes and time to surgery remains uncertain. In this study, we sought to examine the effect of time to surgery on outcomes in a relatively focused group of patients with severe TBI: those undergoing craniectomy for SDH.

\section{Materials and methods}

Following Institutional Review Board approval (Protocol Assurance \#2011-P-000269/1), we identified a consecutive, retrospective cohort of patients undergoing surgical treatment for SDH at our center between 2006 and 2012.

\subsection{Inclusion and exclusion criteria}

Patients of all ages were included if their SDH was traumatic in origin. Following head CT scan, patients with acute SDH $>1 \mathrm{~cm}$ in thickness or resulting in $>0.5 \mathrm{~cm}$ of midline shift underwent surgical evacuation as soon as possible, congruent with guidelines from the Brain Trauma Foundation. All cases were performed on an emergent basis. Patients were excluded from analysis if they did not have a documented time of injury. Additionally, we excluded all patients with penetrating trauma (for example, gunshot wound), cerebrovascular injury, epidural hematoma, or intraparenchymal hemorrhage greater than $30 \mathrm{ml}$. As per departmental practice pattern, patients with acute traumatic SDH who presented with significant midline shift underwent prophylactic craniectomy. Patients undergoing craniotomy (bone flap replaced at the conclusion of the procedure) were also not included, as they were thought to represent a separate subgroup of patients with less severe injury. 


\subsection{Variable and outcome selection}

Age, sex, transfer status from other hospital, injury severity score ${ }^{13}$, presence of fixed pupil(s), midline shift on CT scan, subdural thickness, coma (Glasgow Coma Scale [GCS] score $\$ 8)$ on presentation to the emergency department, whether the patient was taking aspirin, whether the patient was anticoagulated with warfarin, and time interval to surgery were extracted from the medical record. Time to surgery was defined as the documented time of injury to time of incision. To account for brain atrophy and/or propensity for cerebral edema in different patients, we also calculated the ratio of midline shift to SDH thickness. These variables were each selected based on previous reports of their association with outcomes following SDH. ${ }^{3,4,14-19}$ Perioperative resuscitation associated characteristics were also recorded, including hypotension (systolic blood pressure of $<90 \mathrm{mmHg}$ observed in the emergency department or intraoperatively), hypoxemia ( $\mathrm{PaO} 2<60 \mathrm{mmHg}$; $\mathrm{O} 2$ saturation $<90 \%$ ), location of intubation (pre-hospital, emergency department, or operating room), operating room blood product transfusion (measured in units administered), operating room fluid administration (colloid and crystalloid), estimated blood loss, and urine output.

Our primary outcome was in-hospital mortality. Secondary outcomes included the requirement for tracheostomy and/or gastrostomy, both objective data points that were readily accessible from the medical record. In-hospital complications were recorded, in addition to causes of death.

\subsection{Statistical analysis}

Univariate analyses were performed for each variable and outcome measure. Comparisons of categorical variables were made with the Pearson $\chi^{2}$ test and comparison of continuous variables with non-normal distributions were made by the use of nonparametric statistics (Mann-Whitney U test). We then constructed a multiple logistic regression model by first entering all variables into the model and then using stepwise backward elimination (Wald method) to generate the most parsimonious model. All statistical tests were two-sided, and $p$ $<0.05$ was predetermined to establish statistical significance. All analyses were performed using The Statistical Package for the Social Sciences version 21 (SPSS Inc., Chicago, IL, USA).

\section{Results}

Of the 522 patients presenting to our center with SDH, 45 met study criteria (Table 1,2). The mean age of the group was 45.7 years (standard deviation $=19.8$ ), and consisted of 34 men (75.6\%) and 11 women (24.4\%). The majority (62.2\%) of patients were transferred from a referring hospital, and $29(64.4 \%)$ were comatose on arrival (GCS $\$ 8)$. The average time to surgery was 326 minutes, or 5.4 hours (standard deviation $=222$ minutes). Of these patients, a total of $11(24.4 \%)$ died during their hospitalization. The causes of death were brain death $(n=3)$, withdrawal of care secondary to neurological prognosis $(n=6)$, complications related to abdominal compartment syndrome $(\mathrm{n}=1)$, and intraoperative cardiac arrest $(\mathrm{n}=1)$. Complications occurred in all but 16 patients (Table 3$)$. Nineteen $(42.2 \%)$ required tracheostomy or gastrostomy placement. 
Univariate analysis showed significant associations between in-hospital mortality (primary outcome) and both interhospital transfer $(p=0.048)$ and increasing injury severity score $(p=$ 0.018 ) (Table 4 ). We also found that faster time to surgery was significantly associated with greater mortality $(p=0.010)$. The presence of a fixed pupil approached significance ( $p=$ $0.050)$. Factors associated with tracheostomy or gastrostomy placement (secondary outcome) were male sex $(p=0.028)$, midline shift $(p=0.034)$, coma (GCS $\$$ ) at presentation $(p=0.024)$, and anticoagulation with warfarin $(p=0.036)$. Time to injury was not significantly associated with requirement for tracheostomy or gastrostomy in univariate analysis.

In our multivariate model for mortality, stepwise backward elimination identified four factors with significant effects (Table 5$)$. These were age $(p=0.031)$, injury severity score ( $p=0.009)$, time to surgery $(p=0.018)$, and antiplatelet therapy $(p=0.010)$. In a multiple regression model for tracheostomy or gastrostomy, significant factors were male sex ( $p=$ $0.009)$, ratio of midline shift to subdural thickness $(p=0.033)$, and coma (GCS $\$$ ) on presentation $(p=0.011)$ (Table 6).

Comparison of perioperative resuscitation-associated factors between survival categories did not demonstrate any significant differences (Table 7).

\section{Discussion}

In this study, we sought to determine the effect of time to surgery on outcomes in patients with SDH requiring emergent craniectomy. We utilized multiple logistic regression modeling to determine the contribution of multiple clinical variables that have been previously reported to be associated with outcome. In our model, injury severity score and age were associated with increased mortality, while antiplatelet therapy and time to surgery had a seemingly protective effect. These results suggest that shorter time to surgery may not result in better outcomes, contrary to the results of a few previous reports. ${ }^{3}$

Previous studies that have found faster time to surgery to be associated with worse outcomes have been met with skepticism because of the argument that patients who had more severe injuries tended to be operated on sooner than others. This selection bias can certainly skew results without correcting for potential confounders. For example, in a study by Dent et al. that reported earlier surgery was associated with worse outcomes, patients who had surgery within 4 hours tended to have lower GCS scores, more severe intracranial injuries, and greater incidence of brain herniation than patients who had later surgery. However, the authors did not control for these confounding factors. ${ }^{11}$ To avoid a similar bias, we limited our sample of patients to those who had limited additional structural brain injury other than SDH. Our multivariate model controlled for injury severity score, GCS score, and brainstem compression (as signified by fixed pupils) among other variables, which greatly reduces the likelihood that our results were confounded by injury severity.

Why might faster times to surgery be associated with higher mortality? It is possible that pre-surgical stabilization and resuscitation, which may cause a delay to surgery, could contribute to improved survival. Indeed, a few studies have found that mortality is increased 
among patients with severe TBI who present with hypoxia or hypotension, suggesting that treatment of these systemic perturbations before surgical intervention may be of greater importance than already thought. ${ }^{20-22}$ Accurate assessment of this phenomenon would require detailed knowledge of both pre-hospital and referring hospital variables, which were not routinely available in our medical records. In hospital observation of hypotension or hypoxemia failed to demonstrate a significant difference between categories of survival. Other perioperative characteristics of resuscitation available in the medical record, such as blood product transfusion and urine output also failed to demonstrate differences between the two groups. It is possible that a type II error contributed to these findings, especially considering the sample size available.

Another finding in our study was a significant association between premorbid aspirin use and lower mortality $(p=0.010)$. Although some studies have shown that antiplatelet activity increases the incidence of $\mathrm{SDH}^{23}$, few have directly examined the effect of aspirin on outcomes following traumatic injury. Recently, Harr and colleagues reported that prehospital antiplatelet therapy was associated with reduced incidence of lung dysfunction, multiple organ system failure, and mortality in trauma patients. ${ }^{24}$ They suggested that the pathogenesis of post-injury organ dysfunction might be at least in part mediated by fibrin deposition, microthrombosis formation, and inflammation, all of which are associated with platelet activation and may be mitigated by aspirin use. ${ }^{24}$ There is some evidence that a similar effect occurs in the brain following TBI - post-traumatic coagulopathy can result in a disseminated intravascular coagulation phenomenon, causing intravascular microthromboses and ischemia. ${ }^{25}$ Indeed, histopathological ${ }^{26}$ and diffusion-weighted MRI studies ${ }^{27}$ have confirmed the presence of ischemic lesions caused by intravascular microthromboses following TBI. The association between premorbid aspirin use and lower mortality in our study may reflect protective effect of aspirin on the development of intravascular microthromboses, a potentially important contributor to outcomes following traumatic injury.

\subsection{Strengths and limitations}

The main strengths of our study are the strict inclusion criteria that limited the potential for extraneous confounding factors. For example, it is well regarded that the outcomes from acute epidural hematoma and SDH are different, which is why we attempted to limit our patient population to a single disease entity. By increasing the homogeneity of our sample, we also limited our sample size and the generalizability of these findings to other populations with TBI. Also limiting our sample size was the large proportion of patients who did not have a documented time of injury. Sometimes, this was a result of circumstances, as in the cases where patients are "found down" without any witness or historical account available. Other times, there is a lapse in documentation, highlighting the need for efforts to collect accurate data for both clinical care and research.

Our use of a logistic regression model allowed for the interpretation of numerous factors that have been shown to be associated with outcome. Nevertheless, like all retrospective studies, our findings may have been skewed by selection bias. In particular, our sample may have been biased against patients with very severe injury who died before arrival at our center and 
were therefore not considered in this study. This could have affected our results by omitting severely injured patients who might have benefited from early surgery. Future, prospective studies are needed to validate some of the preliminary findings suggested here.

\section{Conclusions}

In patients undergoing craniectomy for $\mathrm{SDH}$, the time interval from injury to surgery is inversely related to mortality. Additionally, antiplatelet therapy is associated with decreased mortality. Systemic effects of traumatic injury appear to play a significant role in patients with TBI. The pre-surgical period represents an important and modifiable time period that warrants further study.

\section{References}

1. Kalanithi P, Schubert RD, Lad SP, Harris OA, Boakye M. Hospital costs, incidence, and inhospital mortality rates of traumatic subdural hematoma in the United States. Journal of Neurosurgery. 2011; 115:1013-1018. [PubMed: 21819196]

2. Compagnone C, Murray GD, Teasdale GM, Maas AI, Esposito D, Princi P, et al. The management of patients with intradural post-traumatic mass lesions: a multicenter survey of current approaches to surgical management in 729 patients coordinated by the European Brain Injury Consortium. Neurosurgery. 2007; 61:232-240. discussion 240-231. [PubMed: 18813166]

3. Seelig JM, Becker DP, Miller JD, Greenberg RP, Ward JD, Choi SC. Traumatic acute subdural hematoma: major mortality reduction in comatose patients treated within four hours. N Engl J Med. 1981; 304:1511-1518. [PubMed: 7231489]

4. Tian HL, Chen SW, Xu T, Hu J, Rong BY, Wang G, et al. Risk factors related to hospital mortality in patients with isolated traumatic acute subdural haematoma: analysis of 308 patients undergone surgery. Chin Med J (Engl). 2008; 121:1080-1084. [PubMed: 18706221]

5. Haselsberger K, Pucher R, Auer LM. Prognosis after acute subdural or epidural haemorrhage. Acta Neurochir (Wien). 1988; 90:111-116. [PubMed: 3354356]

6. Koç RK, Akdemir H, Öktem IS, Meral M, Menkü A. Acute subdural hematoma: Outcome and outcome prediction. Neurosurgical Review. 1997; 20:239-244. [PubMed: 9457718]

7. Kotwica Z, Brzezinski J. Acute subdural haematoma in adults: an analysis of outcome in comatose patients. Acta Neurochir (Wien). 1993; 121:95-99. [PubMed: 8512021]

8. Wilberger JE Jr, Harris M, Diamond DL. Acute subdural hematoma: morbidity, mortality, and operative timing. J Neurosurg. 1991; 74:212-218. [PubMed: 1988590]

9. Wilberger JE Jr, Harris M, Diamond DL. Acute subdural hematoma: morbidity and mortality related to timing of operative intervention. J Trauma. 1990; 30:733-736. [PubMed: 2352302]

10. Stone JL, Rifai MH, Sugar O, Lang RG, Oldershaw JB, Moody RA. Subdural hematomas. I. Acute subdural hematoma: progress in definition, clinical pathology, and therapy. Surg Neurol. 1983; 19:216-231. [PubMed: 6836474]

11. Dent DL, Croce MA, Menke PG, Young BH, Hinson MS, Kudsk KA, et al. Prognostic factors after acute subdural hematoma. J Trauma. 1995; 39:36-42. discussion 42-33. [PubMed: 7636908]

12. Hatashita S, Koga N, Hosaka Y, Takagi S. Acute subdural hematoma: severity of injury, surgical intervention, and mortality. Neurol Med Chir (Tokyo). 1993; 33:13-18. [PubMed: 7680777]

13. Baker SP, o'Neill B, Haddon W Jr, Long WB. The injury severity score: a method for describing patients with multiple injuries and evaluating emergency care. Journal of Trauma-Injury, Infection, and Critical Care. 1974; 14:187-196.

14. Leitgeb J, Mauritz W, Brazinova A, Janciak I, Majdan M, Wilbacher I, et al. Outcome after severe brain trauma due to acute subdural hematoma. Journal of Neurosurgery. 2012; 117:324-333. [PubMed: 22631691]

15. Servadei F. Prognostic factors in severely head injured adult patients with acute subdural haematoma's. Acta Neurochirurgica. 1997; 139:279-285. [PubMed: 9202766] 
16. Stone JL, Lowe RJ, Jonasson O, Baker RJ, Barrett J, Oldershaw JB, et al. Acute subdural hematoma: direct admission to a trauma center yields improved results. J Trauma. 1986; 26:445450. [PubMed: 3701893]

17. Fang MC, Go AS, Chang Y, Borowsky LH, Pomernacki NK, Udaltsova N, et al. Thirty- Day Mortality After Ischemic Stroke and Intracranial Hemorrhage in Patients With Atrial Fibrillation On and Off Anticoagulants. Stroke. 2012; 43:1795-1799. [PubMed: 22539546]

18. Ohm C, Mina A, Howells G, Bair H, Bendick P. Effects of antiplatelet agents on outcomes for elderly patients with traumatic intracranial hemorrhage. J Trauma. 2005; 58:518-522. [PubMed: 15761345]

19. Mina AA, Knipfer JF, Park DY, Bair HA, Howells GA, Bendick PJ. Intracranial complications of preinjury anticoagulation in trauma patients with head injury. J Trauma. 2002; 53:668-672. [PubMed: 12394864]

20. Miller JD, Sweet RC, Narayan R, Becker DP. Early insults to the injured brain. JAMA. 1978; 240:439-442. [PubMed: 660888]

21. Chesnut RM, Marshall LF, Klauber MR, Blunt BA, Baldwin N, Eisenberg HM, et al. The role of secondary brain injury in determining outcome from severe head injury. J Trauma. 1993; 34:216222. [PubMed: 8459458]

22. Fakhry SM, Scanlon JM, Robinson L, Askari R, Watenpaugh RL, Fata P, et al. Prehospital rapid sequence intubation for head trauma: conditions for a successful program. J Trauma. 2006; 60:997-1001. [PubMed: 16688061]

23. Connolly BJ, Pearce LA, Kurth T, Kase CS, Hart RG. Aspirin Therapy and Risk of Subdural Hematoma: Meta-analysis of Randomized Clinical Trials. Journal of Stroke and Cerebrovascular Diseases. 2013; 22:444-448. [PubMed: 23422345]

24. Harr JN, Moore EE, Johnson J, Chin TL, Wohlauer MV, Maier R, et al. Antiplatelet therapy is associated with decreased transfusion-associated risk of lung dysfunction, multiple organ failure, and mortality in trauma patients. Crit Care Med. 2013; 41:399-404. [PubMed: 23263579]

25. Stein SC, Smith DH. Coagulopathy in traumatic brain injury. Neurocritical Care. 2004; 1:479-488. [PubMed: 16174954]

26. Kaufman HH, Hui KS, Mattson JC, Borit A, Childs TL, Hoots WK, et al. Clinicopathological correlations of disseminated intravascular coagulation in patients with head injury. Neurosurgery. 1984; 15:34-42. [PubMed: 6472592]

27. Liu AY, Maldjian JA, Bagley LJ, Sinson GP, Grossman RI. Traumatic brain injury: diffusionweighted MR imaging findings. AJNR Am J Neuroradiol. 1999; 20:1636-1641. [PubMed: 10543633] 
Table 1

Descriptive statistics for continuous variables for the 45 patients who met inclusion criteria

\begin{tabular}{|l|l|l|l|l|}
\hline Factor & Mean & SD & SEM & Range \\
\hline Age, years & 45.73 & 19.828 & 2.956 & $3-85$ \\
\hline Injury severity score & 22.93 & 10.206 & 1.521 & $5-48$ \\
\hline Midline shift, cm & 0.978 & 0.5143 & 0.0767 & $0-2.5$ \\
\hline Subdural thickness, cm & 1.438 & 0.6499 & 0.0969 & $0.8-4.0$ \\
\hline Midline shift : Subdural thickness & 0.743 & 0.40875 & 0.06093 & $0-2.00$ \\
\hline Time to surgery, minutes & 326.42 & 222.482 & 33.166 & $100-1037$ \\
\hline
\end{tabular}

$\mathrm{SD}=$ standard deviation, $\mathrm{SEM}=$ standard error of the mean. 
Table 2

Descriptive statistics for categorical variables for the 45 patients who met inclusion criteria

\begin{tabular}{|l|l|l|l|}
\hline Factor & Categories & Frequency & Percent \\
\hline \multirow{3}{*}{ Sex } & Male & 34 & 75.6 \\
\cline { 2 - 4 } & Female & 11 & 24.4 \\
\hline \multirow{3}{*}{ Transport } & From scene & 17 & 37.8 \\
\cline { 2 - 4 } & Interhospital transfer & 28 & 62.2 \\
\hline \multirow{3}{*}{ Pupils } & Reactive pupils & 28 & 62.2 \\
\cline { 2 - 4 } & Fixed pupil(s) & 17 & 37.8 \\
\hline \multirow{3}{*}{ Anticoagulation (warfarin) } & GCS at presentation to ED >8 & 16 & 35.6 \\
\cline { 2 - 4 } & GCS at presentation to ED $\$ 8$ & 29 & 64.4 \\
\cline { 2 - 4 } & Not anticoagulated & 42 & 93.3 \\
\cline { 2 - 4 } Antiplatelet therapy (aspirin) & Anticoagulated & 3 & 6.7 \\
\cline { 2 - 4 } & No antiplatelets & 39 & 86.7 \\
\hline & Antiplatelets & 6 & 13.3 \\
\hline
\end{tabular}

$\mathrm{ED}=$ emergency department, GCS $=$ Glasgow Coma Scale. 
Table 3

\section{In-hospital complications}

\begin{tabular}{|l|l|}
\hline Type & n \\
\hline Abdominal compartment syndrome & 1 \\
\hline Acute renal failure & 2 \\
\hline Acute respiratory distress syndrome & 1 \\
\hline Bloodstream infection (central line related) & 1 \\
\hline Deep vein thrombosis & 2 \\
\hline Diabetes insipidus & 1 \\
\hline Hydrocephalus requiring permanent cerebrospinal fluid diversion & 1 \\
\hline Infectious colitis & 2 \\
\hline Liver failure & 1 \\
\hline Myocardial infarction & 3 \\
\hline None & 16 \\
\hline Pancreatitis & 1 \\
\hline Pneumonia & 15 \\
\hline Syndrome of inappropriate antidiuretic hormone & 1 \\
\hline Urinary tract infection & 1 \\
\hline Wound infection & 3 \\
\hline
\end{tabular}


Table 4

Univariate analysis of factors associated with mortality (primary outcome) and tracheostomy or gastrostomy (secondary outcome)

\begin{tabular}{|l|l|l|}
\hline Factor & $\begin{array}{l}\text { Association with } \\
\text { mortality, } \boldsymbol{p} \text { value }\end{array}$ & $\begin{array}{l}\text { Association with } \\
\text { tracheostomy/PEG, } \\
\boldsymbol{p} \text { value }\end{array}$ \\
\hline Age, years & 0.411 & 0.696 \\
\hline Sex, male & 0.296 & $\mathbf{0 . 0 2 8}$ \\
\hline Transport (interhospital transfer) & $\mathbf{0 . 0 4 8}$ & 0.260 \\
\hline Injury severity score (increasing) & $\mathbf{0 . 0 1 8}$ & 0.305 \\
\hline Fixed pupil(s) & 0.050 & 0.260 \\
\hline Midline shift, cm & 0.354 & $\mathbf{0 . 0 3 4}$ \\
\hline Subdural thickness, cm & 0.785 & 0.473 \\
\hline Midline shift : Subdural thickness & 0.382 & 0.264 \\
\hline Coma (GCS $\$$ ) on presentation & 0.180 & $\mathbf{0 . 0 2 4}$ \\
\hline Time to surgery, minutes & $\mathbf{0 . 0 1 0}$ & 0.462 \\
\hline Antiplatelet therapy (aspirin) & 0.586 & 0.636 \\
\hline Warfarin alone & 0.711 & $\mathbf{0 . 0 3 6}$ \\
\hline
\end{tabular}

GCS = Glasgow Coma Scale, $\mathrm{PEG}=$ percutaneous endoscopic gastrostomy.

Significant $p$ values are in bold. 
Table 5

Factors significantly associated with mortality (primary outcome) in multiple logistic regression model

\begin{tabular}{|l|l|l|l|}
\hline Factor & OR & $\mathbf{9 5 \%} \mathbf{C I}$ & $\boldsymbol{p}$ value \\
\hline Age, years & 1.066 & $1.006-1.129$ & 0.031 \\
\hline Injury severity score (increasing) & 1.146 & $1.035-1.270$ & 0.009 \\
\hline Antiplatelet therapy (aspirin) & 0.019 & $0.001-0.392$ & 0.010 \\
\hline Time to surgery, minutes & 0.984 & $0.971-0.997$ & 0.018 \\
\hline
\end{tabular}

$\mathrm{CI}=$ confidence interval, $\mathrm{OR}=$ odds ratio. 


\section{Table 6}

Factors significantly associated with tracheotomy or gastrostomy placement in multiple logistic regression model

\begin{tabular}{|l|l|l|l|}
\hline Factor & OR & $\mathbf{9 5 \%}$ CI & $\boldsymbol{p}$ value \\
\hline Sex (male) & 0.036 & $0.003-0.0437$ & 0.009 \\
\hline Midline shift : Subdural thickness & 3.329 & $1.100-10.072$ & 0.033 \\
\hline Coma (GCS \&8) on presentation & 0.161 & $0.039-0.660$ & 0.011 \\
\hline
\end{tabular}

$\mathrm{CI}=$ confidence interval, $\mathrm{GCS}=$ Glasgow Coma Scale, $\mathrm{OR}=$ odds ratio. 
Table 7

Comparison of resuscitation-associated factors between groups of patients who survived versus died

\begin{tabular}{|l|l|l|}
\hline Factor & $\boldsymbol{p}$ value & Interpretation \\
\hline Hypotension & 0.62 & No difference between categories of survival \\
\hline Hypoxemia & 0.06 & No difference between categories of survival \\
\hline Location of intubation & $0.33-0.51$ & No difference between categories of survival \\
\hline Packed red blood cell transfusion & 0.08 & No difference between categories of survival \\
\hline Platelet transfusion & 0.41 & No difference between categories of survival \\
\hline Fresh frozen plasma transfusion & 0.11 & No difference between categories of survival \\
\hline Crystalloid/colloid transfusion volume & 0.74 & No difference between categories of survival \\
\hline Estimated blood loss & 0.65 & No difference between categories of survival \\
\hline Urine output & 0.67 & No difference between categories of survival \\
\hline
\end{tabular}

